\title{
Distortion-product otoacoustic emission growth curves in neonates
}

\author{
Tania Alves Barbosa ${ }^{1}$, Alessandra Spada Durante² ${ }^{2}$ Lidio Granato ${ }^{3}$ \\ -Speech Therapist, Master in Health Sciences, Faculty of Medical Sciences of Santa Casa de São Paulo, São Paulo, SP, Brazil \\ 2Professor Assistant, Faculty of Medical Sciences of Santa Casa de São Paulo, São Paulo, SP, Brazil \\ 3Professor, Department of Otorhinolaryngology, Faculty of Medical Sciences of Santa Casa de São Paulo, São Paulo, SP, Brazi
}

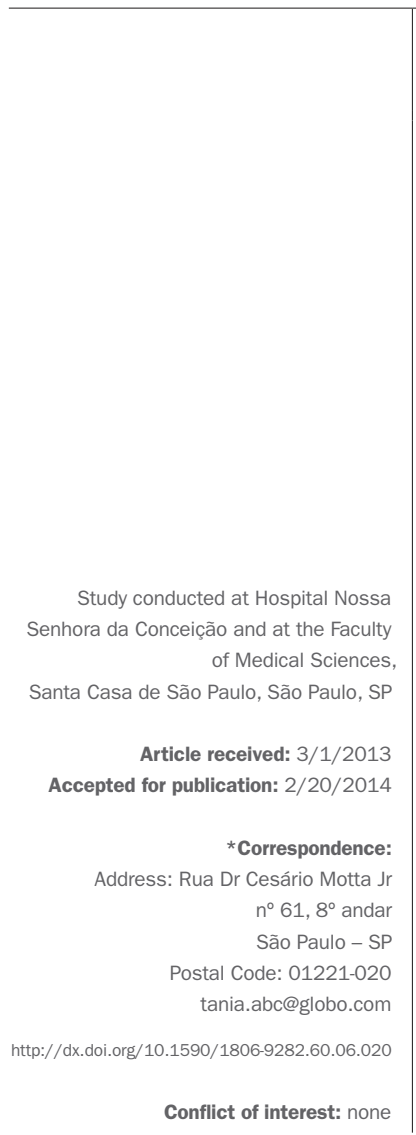

\section{SUMmarY}

Background: The recording of otoacoustic emissions (OAE) enabled us to prove that the cochlea is able not only to receive sounds but also to produce acoustic energy. Through the use of distortion-product otoacoustic emission measurements, the growth of the response was seen according to the intensity of the sound stimulus presented (growth curve).

Objective: to determine the thresholds for the emergence of distortion-product otoacoustic emissions (DPOAE) on frequencies of 2000 and $4000 \mathrm{~Hz}$ with a stimulus varying from 20 to $65 \mathrm{~dB}$ SPL, and to establish the slope values obtained in the growth curves.

Methods: 39 neonates aged 5 to 28 days without risk indicators of hearing loss were studied. The DPOAE growth curves were obtained on the frequencies from $2000 \mathrm{~Hz}$ and $4000 \mathrm{~Hz}$ with a level of intensity ranging from 20 to $65 \mathrm{~dB}$ SPL divided into two paradigms (20 to 40dB SPL and 40-65dB SPL).

Results: there was a statistically significant difference in the thresholds for the emergence of DPOAE depending on the criteria used. The thresholds were on average higher at $4000 \mathrm{~Hz}$ than $2000 \mathrm{~Hz}$ and the slope was higher on average at $2000 \mathrm{~Hz}$ than $4000 \mathrm{~Hz}$, although not statistically significant in either case.

Conclusion: the thresholds were on average $30 \mathrm{~dB}$ SPL at $2000 \mathrm{~Hz}$ and $35 \mathrm{~dB}$ SPL at $4000 \mathrm{~Hz}$. The slope values varied between 3 and 4 on average, reaching 15 in some cases.

Keywords: spontaneous otoacoustic emissions, hearing tests, hearing, newborn.

\section{INTRODUCTION}

The recording of otoacoustic emissions (OAE) is a method used for the detection of hearing changes of cochlear origin. ${ }^{1}$ Among other functions, the cochlea amplifies sounds, which is performed nonlinearly in healthy cochlea, that is, there is a compression mechanism within the cochlea that enables the amplification to occur at different proportions depending on the intensity of the stimulus (weak, medium and strong). For weak sounds the amplification is linear, and for medium intensity sounds the amplification is lower, which is called cochlear compression, Ruggero. ${ }^{2}$
Direct measurements of cochlear nonlinearity are not possible. As a result, access to the nonlinearity of the human cochlea has to be undertaken with noninvasive and indirect measures, according to Gorga et al.. ${ }^{3}$

With the measurement of distortion-product otoacoustic emissions (DPOAE) it is possible to verify the growth in the response according to the level of intensity of the sound stimulus presented (growth curve), as per Abdala. ${ }^{4}$

The study of the DPOAE growth function has proven to be a very favorable instrument for access to and 
understanding of cochlear physiology, especially compression mechanisms and cochlear nonlinearity, as well as the function of outer hair cells. The realization of the DPOAE growth curve, also known as the input/output (IO) growth function makes it possible to obtain the DPOAE threshold. ${ }^{5}$ The occurrence of DPOAE compression in newborns can be interpreted as an indication of reduction in gain from cochlear amplification with an increase in the stimulus level. The presence of compression in this phase, in addition to suggesting cochlear integrity, is a strong indicator that already at birth the peripheral function enables greater amplification of sounds with a low intensity level, favoring auditory tasks that require temporal resolution ability. Nonlinearity is important for recognizing speech in a noisy environment. ${ }^{6}$ The sounds are dynamic, with constant changes in the spectrum, amplitude, spatial location and duration parameters. The process of perceiving quick changes in the pattern of the stimulus, integrating information occurring over time, is denominated temporal processing. Knowledge of the occurrence of this pattern at birth confirms the hypothesis of maturity in the peripheral auditory system in the neonatal phase, predisposing the development of temporal resolution ability in this phase. ${ }^{7}$

Thus, importance of research on the possible clinical applications of this test emerges. Cochlear physiology represents an important subject for study and has become a major motivation in this work: to obtain a more specific understanding of the cochlea and its operation, thereby collaborating when there are losses to these cochlear functions, mainly aimed at the neonatal population, where intervention and early stimulation measures can be developed, as well as complementing newborn hearing screening (NHS). Non-linear amplification of the sound made by the cochlea indicates that it is working normally, especially in relation to the OHC function, and a linear amplification for all levels of stimulus intensity indicates a cochlea with abnormalities. ${ }^{8}$

In alterations to the middle ear only, the function of the OHCs is not compromised, so the growth curve obtained will have the same configuration as a normal examination, i.e. with nonlinear amplification, presenting only an increased DPOAE threshold. The realization of DPOAE growth curves in babies who "fail" the Newborn Hearing Screening Program would be important and useful to differentiate the presence of amniotic fluid/vernix in the EAM (external auditory meatus) and/or tube dysfunction from a cochlear abnormality, ${ }^{9}$ optimizing the referral for audiological diagnosis.
Obtaining the thresholds for the emergence of DPOAE helps in the recommendation of hearing aids in the cases of mild to moderate hearing losses, increasing the information provided to the professional who will perform this procedure. ${ }^{10}$

In addition to its possible applications, this line of research has not been well explored in newborns, meaning that studies in this area and on this specific population are justified.

\section{Objective}

To determine the DPOAE emergence thresholds at the frequencies of $2000 \mathrm{~Hz}$ and $4000 \mathrm{~Hz}$ with a variation in the stimulus of 20 to $65 \mathrm{dBNPS}$.

To establish the slope values obtained in the growth curves at the frequencies of $2000 \mathrm{~Hz}$ and $4000 \mathrm{~Hz}$ as a function of the intensity.

\section{Methods}

This is a prospective, cross-sectional and descriptive study. This was approved by the Research Ethics Committee of São Paulo's Holy House of Mercy Brotherhood (project 277/10) and was conducted at the institution's Speech Pathology Sector, with newborns born between March and August 2011. All of the newborns tested were born at São Paulo's Holy House of Mercy Brotherhood and were tested after being discharged from hospital. At that time, the parents or guardians received a referral for realization of newborn hearing screening at the hospital's Speech Pathology Sector, at scheduled dates and times, within 4 weeks of birth, enabling investigation within the neonatal period.

\section{Case-based reasoning}

Inclusion criteria:

- Neonates born to term, over 37 weeks based on the New Ballard Score classification. ${ }^{11}$

- No risk indicator for hearing loss according to the JCIH. ${ }^{12}$

- With OAE by transient stimuli and/or distortion product present in the newborn hearing screening program.

- Signed informed consent form.

Exclusion criteria:

- Newborns who did not sleep or woke up during the exam.

This study included 39 newborns. A total of 14 exams were conducted on each newborn. The total assessment 
period was an average of 30 minutes per newborn in a single session.

\section{Characterization of the sample}

51 newborns were invited to participated in the study, however 12 did not maintain the conditions required to realize the exam either because they woke up during the assessment, did not sleep for testing to begin, or did not respond in the newborn hearing screening after otoacoustic emissions. Thus, 39 newborns participated in the study, $21(53.8 \%)$ male and 18 (46.2\%) female. The perinatal characteristics of the newborns can be viewed in Table 1 .

\section{Equipment}

The equipment used for the collection of the data in the study was the ILO V6 Otodynamics Analyzer, Cochlear Emissions Analyzer ILO292 DP Echoport Version 6, Otodynamics, London. A newborn probe was used for insertion (SGS-8) connected to channel A of the external unit of the ILO equipment.

\section{Procedure}

The exams were performed in a soundproof booth. The shape of the stimulus curve was monitored in the ear in 'real-time', ensuring the quality and reliability of the data collected. The probe was acoustically calibrated daily in a cubic centimeter cavity, for assessment of newborns. No otoscopy was conducted before the procedure.

In a state of natural sleep, the newborn was positioned to conduct the assessment, starting $50 \%$ of the exams in the right ear and $50 \%$ in the left ear, thus ensuring no interference from the first ear tested.

The probe was adapted to capture DPOAE growth curves (GC) in the first ear to be tested, results being recorded with the following order of procedures:

- DPOAE GC at $2000 \mathrm{~Hz}$ general paradigm

- DPOAE GC at $2000 \mathrm{~Hz}$ paradigm 1
- DPOAE GC at $2000 \mathrm{~Hz}$ paradigm 2.

- DPOAE GC at $4000 \mathrm{~Hz}$ paradigm 1.

- DPOAE GC at $4000 \mathrm{~Hz}$ paradigm 2.

Where:

- Paradigm 1 (P1): L2 from 20 to 40 dB NPS.

- Paradigm 2 (P2): L2 from 40 to 65 dB NPS.

- General Paradigm (GP): L2 from 35 to 65 dB NPS

Next, the same procedures were repeated in the second ear.

The DPOAE GC were obtained for paradigms P1 and P2 based on the hypothesis that the slope would be higher (greater incline of the curve) in weak sounds (20 to $40 \mathrm{~dB}$ SPL) and lower (lower incline of the curve) in midrange sounds ( 40 to $65 \mathrm{~dB}$ SPL).

The quality of each exam was observed, ensuring equal assessment conditions with regard to the placement of the probes, stimulus intensity, stability and noise level. Thus, although the study of OAE in the neonatal population is delicate, the reliability of the response observed as increased.

The DPOAE growth curve was obtained for both ears. Two pure tones with primary frequencies denominated $\mathrm{F} 1$ and $\mathrm{F} 2$ were presented. The responses for analysis were obtained at $2 \mathrm{~F} 1-\mathrm{F} 2$, with $\mathrm{F} 1 / \mathrm{F} 2=1.22$. The F2 frequencies chosen were $2000 \mathrm{~Hz}$ and $4000 \mathrm{~Hz}$ for being the frequencies used most often in studies with this population. ${ }^{13}$

The intensities (L2) ranged from 20 to $65 \mathrm{~dB}$ SPL divided into three paradigms:

- Paradigm1: L2 (intensity of frequency F2) varied from 20 to $40 \mathrm{~dB}$ SPL with a $3 \mathrm{~dB}$ interval.

- Paradigm2: L2 (intensity of frequency F2) varied from 40 to $65 \mathrm{~dB}$ SPL with a $3 \mathrm{~dB}$ interval.

- General paradigm: L2 (intensity of frequency F2) varied from 35 to $65 \mathrm{~dB}$ SPL with a $5 \mathrm{~dB}$ interval.

TABLE 1 Baseline characteristics

\begin{tabular}{|c|c|c|c|c|c|}
\hline & Weight (g) & $\begin{array}{l}\text { Gestational age } \\
\text { (weeks) }\end{array}$ & $\begin{array}{l}\text { Days of life upon } \\
\text { assessment }\end{array}$ & 1 minute Apgar & 5 minute Apgar \\
\hline Mean & 3337.4 & 39.2 & 12.72 & - & - \\
\hline Median & 3375 & 39 & 10 & 9 & 10 \\
\hline SD & 471.2 & 0.9 & 5.75 & 0.6 & 0.5 \\
\hline Minimum & 2290 & 38 & 5 & 7 & 9 \\
\hline Maximum & 4085 & 41 & 28 & 9 & 10 \\
\hline
\end{tabular}

SD: standard deviation; N: number of newborns. 
- The intensity of L1 (intensity of frequency 1 ) was adjusted using the formula L1 $=0.4 \mathrm{~L} 2+39$ from Kummer et al. ${ }^{14}$

The exams were finalized when the background noise was equal to or lower than $0 \mathrm{~dB}$ SPL after a minimum of three scans.

The following criteria were adopted to analyze the response in the signal to noise ratio $(\mathrm{S} / \mathrm{N})$ :

- Lim0: intensity at which the $\mathrm{S} / \mathrm{N}$ ratio is greater than or equal to zero - this was called Lim0 (threshold zero).

- Lim6: intensity at which the $\mathrm{S} / \mathrm{N}$ ratio is greater than or equal to six - this was called Lim6 (threshold six).

To obtain the slope, three criteria were established in accordance with the intensities established:

- $\mathbf{G P}=$ intensity varying from 35 to $65 \mathrm{~dB}$ SPL at $2 \mathrm{kHz}$ in $5 \mathrm{~dB}$ intervals.

- $\mathbf{P 1}=$ intensity varying from 20 to $40 \mathrm{~dB}$ SPL at $2000 \mathrm{~Hz}$ and $4000 \mathrm{~Hz}$ in $3 \mathrm{~dB}$ intervals.

- $\mathbf{P 2}=$ intensity varying from 40 to $65 \mathrm{~dB}$ NPS at $2000 \mathrm{~Hz}$ and $4000 \mathrm{~Hz}$ in $3 \mathrm{~dB}$ intervals.

\section{Statistical analysis}

The statistical analysis was undertaken using the program SPSS version 13.0.

The sample calculation was performed using Prime software, considering a significance level of 0.05 .

For the descriptive analysis, the summary measures for quantitative variables were calculated. For qualitative varia- bles, absolute and relative frequencies were obtained and boxplot graphs were generated, as well as Wilcoxon signed-rank test, adopting a significance level of $5 \%$ for all tests.

\section{ResUlts}

Study of DPOAE emergence thresholds obtained with the growth curve

The Lim 0 and Lim 6 thresholds (described in Methods) on the right and left ears at frequencies of $2000 \mathrm{~Hz}$ and $4000 \mathrm{~Hz}$ were compared (Table 2). It was noted that the differences between the parameters used in the research (Lim0 and Lim6) were significant at the frequencies of $2000 \mathrm{~Hz}$ and $4000 \mathrm{~Hz}$ in both ears, but when comparing the left ear and right ear the differences were not significant.

Descriptive study of the slope obtained with the DPOAE growth curve

A descriptive analysis was undertaken of the slope values obtained with the realization of the DPOAE GC at frequencies of $2000 \mathrm{~Hz}$ and $4000 \mathrm{~Hz}$ in the three paradigms used in the study (Table 3 and 4).

The values of the slope obtained in paradigms $\mathrm{P} 1$ and P2 at $2000 \mathrm{~Hz}$ in the right ear and the left ear were compared, and no significant differences were found between them in both ears. When comparing the values of the slope obtained in paradigms $\mathrm{P} 1$ and $\mathrm{P} 2$ at $4000 \mathrm{~Hz}$ in the right ear and the left ear, no significant difference was observed between them. We compared the slope values obtained at frequencies of $2000 \mathrm{~Hz}$

TABLE 2 Distribution of emergence thresholds in decibels obtained in the 2 parameters (Lim0 and Lim6) by ear and by frequency

\begin{tabular}{|c|c|c|c|c|c|c|c|c|}
\hline & \multicolumn{4}{|c|}{ Right ear } & \multicolumn{4}{|c|}{ Left ear } \\
\hline & \multicolumn{2}{|c|}{$2000 \mathrm{~Hz}$} & \multicolumn{2}{|c|}{$4000 \mathrm{~Hz}$} & \multicolumn{2}{|c|}{$2000 \mathrm{~Hz}$} & \multicolumn{2}{|c|}{$4000 \mathrm{~Hz}$} \\
\hline & LO & L6 & Lo & L6 & LO & L6 & LO & L6 \\
\hline Minimum & 22 & 25 & 28 & 28 & 19 & 19 & 19 & 19 \\
\hline Average & 28.13 & 32.32 & 34.69 & 38.66 & 28.97 & 33.27 & 33.62 & 37.21 \\
\hline SD & 6.25 & 7.7 & 6.8 & 8 & 6.4 & 7.2 & 8.4 & 9.4 \\
\hline Median & 25 & 28 & 31 & 37 & 28 & 32.5 & 31 & 37 \\
\hline \multirow[t]{2}{*}{ Maximum } & 53 & 53 & 59 & 44 & 44 & 50 & 62 & 62 \\
\hline & \multicolumn{4}{|c|}{$\mathrm{p}<0.001$} & \multicolumn{2}{|c|}{$p<0.001$} & \multicolumn{2}{|c|}{$p<0.001$} \\
\hline
\end{tabular}

L0: threshold where the signal to noise ratio is greater than or equal to zero; L6: threshold where the signal to noise ratio is greater than or equal to six; SD: standard deviation; p: significance level. 
TABLE 3 Distribution of the slope values obtained at $2000 \mathrm{~Hz}$ in the 3 paradigms for the right ear and left ear

\begin{tabular}{|c|c|c|c|c|c|c|}
\hline & \multicolumn{6}{|c|}{$2000 \mathrm{~Hz}$} \\
\hline & \multicolumn{3}{|c|}{ Right ear } & \multicolumn{3}{|c|}{ Left ear } \\
\hline & P1 & P2 & GP & P1 & P2 & GP \\
\hline Minimum & -0.15 & -0.62 & 2.15 & 0.33 & 0.9 & 1.51 \\
\hline Mean & 3.55 & 3.91 & 10.05 & 3.51 & 4.26 & 8.85 \\
\hline SD & 2.08 & 2.56 & 6.2 & 3.1 & 2.42 & 4.38 \\
\hline Median & 3.16 & 3.21 & 8.98 & 2.33 & 3.74 & 9.16 \\
\hline Maximum & 8.08 & 9.19 & 28.06 & 14.59 & 10.96 & 17.03 \\
\hline
\end{tabular}

SD: standard deviation; P1: 1 paradigm (stimulus intensity ranging from 20 to $40 \mathrm{~dB}$ SPL); P2: paradigm 2 (stimulus intensity ranging from 40 to $65 \mathrm{~dB}$ SPL); GP: general paradigm (stimulus in tensity ranging from 35 to $65 \mathrm{~dB} \mathrm{SPL}$ ).

TABLE 4 Distribution of the slope values obtained at $4000 \mathrm{~Hz}$ in the 2 paradigms for the right ear and left ear

\begin{tabular}{|c|c|c|c|c|}
\hline & \multicolumn{4}{|c|}{$4000 \mathrm{~Hz}$} \\
\hline & \multicolumn{2}{|c|}{ Right ear } & \multicolumn{2}{|c|}{ Left ear } \\
\hline & P1 & P2 & P1 & P2 \\
\hline Minimum & 0.54 & -1.38 & -0.04 & 0.2 \\
\hline Mean & 3.97 & 3.7 & 3.01 & 3.06 \\
\hline SD & 3.17 & 3.51 & 2.65 & 2.84 \\
\hline Median & 2.6 & 2.68 & 2.4 & 2.51 \\
\hline Maximum & 11.58 & 15.9 & 12.33 & 14.44 \\
\hline
\end{tabular}

SD: standard deviation; P1: 1 paradigm (stimulus intensity ranging from 20 to $40 \mathrm{~dB} \mathrm{SPL}$ ); P2: paradigm 2 (stimulus intensity ranging from 40 to $65 \mathrm{~dB} \mathrm{SPL}$ ).

and $4000 \mathrm{~Hz}$ in paradigm 1 in the right ear, and no significant difference between the frequencies was obtained, with the same occurring in paradigm 2 . When comparing the slope values obtained at frequencies of $2000 \mathrm{~Hz}$ and $4000 \mathrm{~Hz}$ in paradigm 1 and paradigm 2, on the left ear, a significant difference was not obtained between frequencies.

\section{Discussion}

The same sequence presented in the results was maintained for the presentation of the discussion.

Cochlear activity is characterized by the absolute signal of the response, and the criterion for identification of the response depends on signal to noise ratio. Therefore, for analysis of the presence of DPOAE, it is necessary for the cochlear response to be above the noise. There is no consen- sus in the literature about the recommended signal/noise ratio. Some studies have used an $\mathrm{S} / \mathrm{N}$ ratio greater than or equal to $3 \mathrm{~dB}$, such as Neely et al. ${ }^{15}$ and Tiradentes et al. ${ }^{16}$ and there are others who have used an $\mathrm{S} / \mathrm{N}$ ratio greater than $6 \mathrm{~dB}$, such as Gorga et al. ${ }^{8}$ and Boege and Janssen. ${ }^{17}$

The equipment used in this study - the ILO V6, analyzes the presence of noise for each pair of frequencies tested considering its mean plus 1 standard deviation. Therefore, the noise level displayed on the monitor screen is higher than the average noise by $6 \mathrm{~dB}$, and therefore the presence of a response can be considered when the $S / N$ ratio is greater than or equal to zero, according to the manufacturer's protocol.

Analyzing the results when obtaining the DPOAE emergence thresholds with the GC, the results showed a significant difference between the two criteria used ( $\mathrm{Lim} 0$ and Lim 6) at the two frequencies $(2000 \mathrm{~Hz}$ and $4000 \mathrm{~Hz})$ in both ears, with the thresholds obtained in $\operatorname{Lim} 0$ smaller on average than those obtained in Lim6. According to a study by Dubno, ${ }^{6}$ significant differences were noted in the emergence thresholds of the DPOAE GC according to the criterion used at $2000 \mathrm{~Hz}$ and $4000 \mathrm{~Hz}$. Comparing the results of the emergence thresholds according to the two criteria used (Lim0 and Lim6) significant differences at $2000 \mathrm{~Hz}$ were noted in both ears, as well as at $4000 \mathrm{~Hz}$, also in both ears, therefore always observing the criterion used in the study should be emphasized for possible comparisons of results.

The emergence thresholds at $2000 \mathrm{~Hz}$ were $30 \mathrm{~dB}$ on average, and $35 \mathrm{~dB}$ on average at $4000 \mathrm{~Hz}$ according to the criteria used (Table 2). These thresholds were lower than those obtained by Dubno ${ }^{6}$ where the responses emerged 
at $50 \mathrm{~dB}$ at $2000 \mathrm{~Hz}$ and $60 \mathrm{~dB}$ at $4000 \mathrm{~Hz}$. In this study we considered three thresholds denominated Threshold1, Threshold 2 and Threshold 3 where:

- Threshold1 (Lim1) = lowest intensity studied where the signal/noise ratio is greater than or equal to $3 \mathrm{~dB}$;

- Threshold2 $(\operatorname{Lim} 2)=$ lowest intensity studied where the signal/noise ratio is greater than or equal to $3 \mathrm{~dB}$ and $2 \mathrm{~F} 1-\mathrm{F} 2$ with a positive value; and

- Threshold3 (Lim3) = lowest intensity studied where the signal/noise ratio is greater than or equal to $3 \mathrm{~dB}$ and subsequent intensities also present a $\mathrm{S} / \mathrm{N}$ ratio greater than or equal to $3 \mathrm{~dB}$, with the emergence threshold considered when it appeared in $70 \%$ of cases.

Therefore, the responses were better at $2000 \mathrm{~Hz}$ compared to $4000 \mathrm{~Hz}$ such as those obtained in the aforementioned study.

When comparing the left ear with the right ear, the differences were not significant due to the number of newborns composing the sample, which was not sufficient for this purpose. These results compare to those obtained by Leme and Carvallo ${ }^{18}$ and Costa et al. ${ }^{19}$ There are studies already established in the literature that show that OAE responses are better in the right ear for the female gender compared to the left ear for the male gender, Leme and Carvallo, ${ }^{18}$ Aidan et al.. ${ }^{20}$ and Durante et al. ${ }^{21}$

The results obtained in the DPOAE growth curves in this study were used to calculate the mean responses for each intensity, using 2F1-F2 and the signal to noise ratio at the frequencies of $2000 \mathrm{~Hz}$ and $4000 \mathrm{~Hz}$, in order to obtain an average curve profile for newborns and to identify the occurrence of any compression pattern for the responses in this age group. To obtain the mean, the grouped results of the left and right ears at each intensity and frequency were used, given that there was no significant difference between them in this study.

The DPOAE GC were obtained for paradigms P1 and P2 based on the hypothesis that the slope would be higher (greater incline of the curve) in weak sounds (20 to $40 \mathrm{~dB}$ SPL) and lower (lower incline of the curve) in midrange sounds ( 40 to $65 \mathrm{~dB}$ SPL). According to Gorga et al. ${ }^{8}$ cochlear gain is higher for weaker stimulus levels, decreasing as the level increases. That is, the cochlea is more com- pressive when stimuli are of medium intensity. In this work, the slope values obtained at $2000 \mathrm{~Hz}$ were lower in P1 than P2 in both ears, and at $4000 \mathrm{~Hz}$ in the right ear P1 was higher than P2, and in the left ear P1 was lower than P2, as in $2000 \mathrm{~Hz}$. These differences were not significant. However, visually, the slope in P1 is greater than in P2. The slope value was higher on average at 2000 $\mathrm{Hz}$ than $4000 \mathrm{~Hz}$ (except for the slope obtained in P1 in the right ear at $4000 \mathrm{~Hz}$, which was greater than the corresponding slope at $2000 \mathrm{~Hz}$ ). If the DPOAE growth curve enables detection of the presence of cochlear compression upon calculating the slope, the numerical results of this study did not make it possible to prove the presence of cochlear compression in the sample, though looking at the growth curve graphs a decrease was seen in the slope of the curves at midrange intensities.

It was not possible to make comparisons with other slope studies obtained in two paradigms, as no work using DPOAE GC in this way was found in the literature. However, a study by Almeida ${ }^{7}$ noted a change in the incline of the curve of the slope from $65 \mathrm{~dB}$, which would be the compression point for the frequencies studied (the DPOAE GC was outlined with stimuli a variation range between 35 and $75 \mathrm{~dB}$ with $5 \mathrm{~dB}$ intervals at $2000 \mathrm{~Hz}$ and $4000 \mathrm{~Hz}$ ). Comparing these results with the present study was not possible, because $65 \mathrm{~dB}$ was the largest stimulus used in the paradigms presented. In studies with adults, the compression point was between 50 and $60 \mathrm{~dB} ., 15,22$

When using the general paradigm the slope values were higher than those obtained in paradigms 1 and 2, but the comparison was not made because of the use of different criteria.

The slope values varied from 3 to 4 on average, reaching 15 in some cases. These maximum values can be attributed to the fact that they were obtained in the newborn population where the OAE responses are better than in other age groups. This fact was discussed with the technical team of the equipment manufacturer (Otodynamic), Peter Bray and Lee Van Middlesworth, who still have no explanation for this finding due to the small number of studies performed with the newborn population. The general paradigm was only applied to part of the sample, and only at $2000 \mathrm{~Hz}$; therefore, it was not compared with the other paradigms (P1 and P2), and the General P slope values were higher than those obtained in P1 and P2. The mean General P slope value was 10.05 in the right ear and 8.85 in the left ear. 


\section{Conclusion}

The emergence thresholds were on average $30 \mathrm{~dB}$ SPL at $2000 \mathrm{~Hz}$ and $35 \mathrm{~dB}$ SPL at $4000 \mathrm{~Hz}$, therefore the best emergence thresholds were at a frequency of $2000 \mathrm{~Hz}$ compared to $4000 \mathrm{~Hz}$.

No difference in the slope values obtained in the DPOAE growth curves were noted, but slopes were steeper at the weakest intensities (P1) and more linear at the moderate intensities (P2) suggesting that the visual analysis of the graph reflects cochlear compression.

\section{ACKNOWLEDGEMENTS}

Peter Bray and Lee Van Middlesworth at Otodynamic, who collaborated with technical knowledge whenever consulted. Prof. Erika Fukunaga for the statistical analysis. Mirtes, Sonia and Daniel, postgraduate secretaries, for their constant and indispensable help. Sadia Hussein Mustafá for the articles obtained and cataloging data. The Faculty of Medical Sciences at the Santa Casa de São Paulo and São Paulo's Holy House of Mercy Brotherhood. Capes for the scholarship grant provided. To those responsible for the newborns that accepted the invitation to participate in this study.

\section{Resumo}

Curva de crescimento das emissões otoacústicas produto de distorção em neonatos.

Introdução: o registro das emissões otoacústicas permitiu comprovar que a cóclea, além de receber os sons, produz energia acústica. Com a medida das emissões otoacústicas - produto de distorção (EOAPD), verifica-se o crescimento da resposta de acordo com a intensidade do estímulo sonoro apresentado (curva de crescimento).

Objetivo: determinar os limiares de surgimento das EOAPD nas frequências de 2.000 e $4.000 \mathrm{~Hz}$ com estímulo de 20 a 65 dB NPS e estabelecer os valores de slope obtidos nas curvas de crescimento.

Métodos: foram estudados 39 neonatos com 5 a 28 dias de vida sem indicadores de risco para perda auditiva. A captação das curvas de crescimento das EOAPD foi realizada em 2.000 e $4.000 \mathrm{~Hz}$ com nível de intensidade variando de 20 a $65 \mathrm{~dB}$ em dois paradigmas ( 20 a $40 \mathrm{~dB}$ NPS e 40 a 65 dB NPS). Resultados: houve diferença estatística significante dos limiares de surgimento das EOAPD dependendo do cri- tério utilizado. Os limiares foram, em média, mais elevados em $4.000 \mathrm{~Hz}$ do que em $2.000 \mathrm{~Hz}$, e o slope foi, em média, maior em $2.000 \mathrm{~Hz}$ do que em $4.000 \mathrm{~Hz}$; porém, com diferença não significante em ambos os casos.

Conclusão: os limiares de surgimento foram, em média, 30 dB NPS em $2.000 \mathrm{~Hz}$ e 35 dB NPS em 4.000 Hz. Os valores do slope variaram, em média, entre 3 e 4, chegando a 15 em alguns casos.

Palavras-chave: emissões otoacústicas espontâneas; testes auditivos; audição; recém-nascido.

\section{References}

1. Kemp DT. Stimulated acoustic emissions from within the human auditory system. J Acoust Soc Am. 1978;64(5):1386-91.

2. Ruggero M, Rich N, Naryan SS, Robles L. Basilar-membrane responses to tones at the base of the chinchilla cochlea. J Acoust Soc Am.1997;101(4):2151-63.

3. Gorga MP, Neely ST, Dierking DM, Kopun J, Jolkowski K, Groenenboom $\mathrm{K}$, et al. Low-frequency and high-frequency cochlear nonlinearity in humans. J Acoust Soc Am. 2007;122(3):1671-80

4. Abdala C. Distorcion product otoacoustic emission (2fi-f2) amplitude growth in human adults and neonates. House Ear Institute. J Acoust Soc. Am. 2000; 107(1):446-56

5. Kemp DT. Otoacoustic emissions, their origin in cochlear function, and use. Br Med Bull. 2002;63:223-41.

6. Dubno JR, Horwitz AR, Ahlstrom JB. Estimates of basilar-membrane nonlinearity effects on masking of tones and speech. Ear Hear. 2007;28(1):2-17.

7. Almeida PP. Crescimento das emissões otoacústicas evocadas-produto de distorção: estudo em neonatos [Dissertação] São Paulo: Faculdade de Medicina, Universidade de São Paulo; 2010.

8. Gorga MP, Neely ST, Dorn PA, Konrad-Martin D. The use of distorcion product otoacoustic emission suppression as an estimate of response growth. J Acoust Soc Am. 2002;111(1):271-84

9. Gehr DD, Janssen T, Michaelis CE, Deingruber K, Lamm K. Middle ear and cochlear disorders result in different DPOAE growth behaviour:implications for the differentiation of sound conductive and cochlear hearing loss. Hear Res. 2004;193(1-2):9-19.

10. Janssen T, Niedermeyer HP, Arnold W. Diagnostics of the cochlear amplifier by means of distortion product otoacoustic emissions. ORL J Otorhinolaryngol Relat Spec. 2006;68(6):334-9.

11. Ballard JL, Khoury JC, Wedig K, Wang L, Eilers-Walsman BL, Lipp R. New Ballard Score, expanded to include extremely premature infants. Joint Committee on Infant Hearing 2007 Position Statement. ASHA. 1994;36:38

12. Haddad GG, Green TP. Diagnostic approach to respiratory disease. In: Kliegman RM, Behrman RE, Jenson HB, Stanton BF, editors. Nelson textbook of pediatrics. $19^{\text {th }}$ Philadelphia: Saunders Elsevier; 2011. chapter 366.

13. Almeida PP, Sanches SGG, Carvallo RMM. Limiar da função de crescimento das emissões otoacústicas por produto de distorção em neonatos Pró Fono. 2010;22(4):409-14.

14. Kummer P, Janssen T, Wolfgang A. The level and growth behavior of 2f1-f2 distortion product otoacoustic emission and its relationship to auditory sensitivity in normal heraring and cochlear hearing loss. J Acoust Soc Am. 1998;103(6):3431-44

15. Neely ST, Johnson TA, Kopun J, Dierking DM, Gorga MP. Distortion-product otoacoustic input/output characteristics in normal-hearing and hearingimpaired human ears. J Acoust Soc Am. 2009;126(2):728-38.

16. Tiradentes JB, Coube CZV, Costa Filho OA. Estudo do padrão de respostas das curvas de crescimento (dp growth) das emissões otoacústicas produto 
de distorção em indivíduos com audição normal. Rev Bras Otorrinolaringol. 2002;68(1):21-6

17. Boege P, Janssen T. Pure-tone threshold estimation from extrapolated distortion product otoacoustic emission $\mathrm{I} / \mathrm{O}$ - functions in normal and cochlear hearing loss ear. J Acoust Soc Am. 2002;111(4):1810-8.

18. Leme VN, Carvallo RMM. Nível de emissões otoacústicas por estímulo transiente e por produto de distorção em neonatos com e sem risco para perda auditiva. J Bras Fonoaudiol. 2005;(23):388-93.

19. Costa JMD, Almeida VF, Oliveira CACP, Sampaio ALL. Emissões otoacústicas por estímulo transiente e por produto de distorção em recém-nascidos prematuros. Arq Int Otorrinolaringol.2009;13 (3);309-16
20. Aidan D, Lestang P, Avan P, Bonfils P. Characteristics of transient evoked otoacoustic emissions (TEOEs) in neonates. Acta Otolaryngol. 1997;117(1):25-30.

21. Durante AS, Carvallo RMM, Costa FS, Soares JC. Characteristics of transient evoked otoacoustic emission in newborn hearing screening program. PróFono. 2005;17(2):133-40.

22. Sanches SGG, Sanchez TG, Carvallo RMM. Influence of cochlear function on auditory temporal resolution in tinnitus patients. Audiol Neurootol. 2010;15(5)273-81. 